\title{
Mechanisms of depressed delayed-type hypersensitivity in rheumatoid arthritis: the role of protein energy malnutrition
}

\author{
PAULEMERY, ${ }^{1}$ GABRIEL PANAYI, ${ }^{1}$ DEBORAH SYMMONS, ${ }^{1}$ AND \\ G I LL B ROWN ${ }^{2}$
}

From the ${ }^{1}$ Departments of Medicine and Rheumatology and the ${ }^{2}$ Department of Dietetics, Guy's Hospital, London SE1 9RT

SUMMARY The presence of anergy and its relationship to malnutrition was investigated in patients with rheumatoid arthritis (RA) and in controls. A generalised reduction in delayed cutaneous hypersensitivity to 7 recall antigens were found in 104 RA patients compared with 67 controls. No measure of the disease was capable of predicting cutaneous anergy, which was present in $36 \%$ of patients but none of the controls. A detailed dietary assessment in $30 \mathrm{RA}$ patients and 30 controls revealed little evidence of clinically important malnutrition. It is therefore concluded that the cutaneous anergy of rheumatoid arthritis is not a consequence of nutritional factors.

Abnormalities of cell mediated immunity (CMI) are thought to be of fundamental importance in rheumatoid arthritis (RA). ${ }^{1}$ Delayed cutaneous hypersensitivity $(\mathrm{DCH})$ has been used as an in-vitro measure of CMI, and both normal and depressed $\mathrm{DCH}$ have been reported in $\mathrm{RA},{ }^{23}$ the more recent studies concluding that a depression of $\mathrm{DCH}$ does exist but without agreement over its relevance or cause. $^{34}$

Malnutrition has a profound effect on $\mathrm{CMI},{ }^{5}$ and adults and children with protein energy malnutrition (PEM) have impaired DCH with the number and size of positive skin reactions being reduced. ${ }^{6}$ PEM also depresses the proportion and absolute number of $T$ lymphocytes, ${ }^{7}$ alters the ratio of $T$ cell subsets, ${ }^{8}$ and reduces lymphocyte transformation to mitogens and antigens.9 The potential to reverse these 'immune changes' with nutritional supplements has been demonstrated. ${ }^{910}$ There has been little recent work on nutrition in RA with scanty or no reference to arthritis in nutritional textbooks. ${ }^{11}{ }^{12}$ Yet RA is a systemic disease with weight loss often being a prominent feature and may be due to a variety of mechanisms: disease activity, anorexia (induced both by the illness and by anti-inflammatory drugs), and difficulties in buying and cooking food. ${ }^{13}$ With the

Accepted for publication 13 July 1983

Correspondence to Professor G. S. Panayi, Department of Medicine, Guy's Hospital London SE1 9RT. availability of standardised, reproducable methods of testing DCH and more sophisticated methods of dietary assessment we decided to investigate the relationship, if any, between DCH and nutritional state in RA.

\section{Patients and methods}

Patients. 104 consecutive patients were selected who had classical or definite RA, both inpatients and outpatients; patients on immunosuppressive drugs (including prednisolone $>5 \mathrm{mg} /$ day) were excluded. All patients were taking a nonsteroidal antiinflammatory drug. Sixty-seven controls were taken from a similar population of rhe umatology patients but without inflammatory joint diseases or systemic illness. All patients were skin tested and RA patients assessed for disease activity. In addition the first $\mathbf{3 0}$ RA patients and a similar number of age and sex matched controls underwent detailed dietary and anthropomorphic assessments.

Skin testing. This was performed on all subjects with a disposable plastic multitest system ('Multitest', Institute Merieux, France) which delivers intradermally 7 standardised recall antigens (tuberculin, tetanus toxoid, diphtheria toxoid, streptococcus, candida, trichophyton, proteus) and a glycerin control in a highly reproducible manner. ${ }^{14}$ The patients were tested between 0900 and $1100 \mathrm{~h}$ and the results 
were read 48 hours later. The mean induration of the skin lesion was measured in 2 perpendicular diameters for each antigen, and a result greater than $2 \mathrm{~mm}$ was considered positive. This, rather than the more often used $5 \mathrm{~mm}$, was chosen as the cut-off point on the manufacturer's instructions and because even small skin test reactions are significant immunological events, correlating with in-vitro lymphocyte transformation. ${ }^{15}$ A patient with one or more positive tests was considered reactive, whereas a patient negative to all 7 antigens was considered anergic. A sum score was calculated by the addition of the mean diameters for each of the 7 antigens.

Disease activity. The ESR, the duration of early morning stiffness (minutes), and the number of active joints (Ritchie index ${ }^{16}$ ) were used as a measure of disease activity.

Anthropomorphic assessments. The ratio of weight $(\mathrm{kg})$ to height $(\mathrm{m})$ squared, the so-called 'body mass index', was calculated for each patient and control, as this has been shown to be a good measure of body fatness in all populations studied.$^{17}$ Mid-arm triceps skin thickness was taken as an index of the subcutaneous fat layer, ${ }^{18}$ albeit a crude one. Albumin and retinol binding protein (measured with radial immunodiffusion plates from Behring Werke, Marburg, West Germany) were also measured as shorter term indicators of PEM. ${ }^{19} 20$

Dietary history. Dietary assessment was made by a trained dietitian of a patient's average week's intake of food. This was subsequently analysed for content by means of a computer program with its reference values taken from McCance and Widdowsons book. ${ }^{21}$ Values were derived for energy (kcal), protein, fat, carbohydrate, dietary fibre, calcium, phosphate, iron, and folate, and vitamins A, B, C, and D.

\section{Results}

Skin test results. DCH in RA patients was significantly depressed in comparison with age and sex matched controls (Table 1). Thus anergy was not seen in controls but was present in $36 \%$ of RA patients $(\mathrm{p}<0 \cdot 001)$. The sum score for the RA group was $6 \cdot 33 \pm 6.99($ mean \pm SD) compared with 18.04 $\pm 9 \cdot 81$ for controls $(p<0 \cdot 001)$. Fig. 1 illustrates the generalised reduction in reactivity in RA patients compared with controls, which can be seen as a shift to the left in that the mode number of positive tests for RA was 0 whereas for controls it was 3. No RA patient had greater than 4 positive reactions.

Comparison of the anergic and reactive subgroups of RA patients did not show any statistically significant differences in any of the factors measured (Table 2). Anergic patients tended to have more severe disease with a nonsignificant increase in disease duration, in seropositivity, and in the proportion with nodules and erosions as compared with the reactive group. There was no significant difference between the 2 groups in measurements of disease activity, but anergic patients had a higher ESR and a longer duration of early morning stiffness. The 2 groups were not distinguished by their drug treatments.

DIETARY AND ANTHROPOMORPHIC RESULTS The 30 RA patients and the 30 controls were representative of the larger groups in terms of sex and age, and for the RA group in terms of disease activity and drug therapy.

The results of the dietary assessments (Table 3) revealed a close correlation between the diets of the RA patients and age and sex matched controls, with no significant differences between the 2 groups for any of the nutrients measured. Common features were the reduced total $\mathrm{kcal}$ and iron and increased protein compared with recommended daily intake (RDI). ${ }^{22}$

Anthropomorphic measurements confirmed the similarity of the RA and control group with no notable differences in body mass index or mid-arm triceps thickness, with only the differences in albumin level reaching the conventional level of significance $(p<0.05)$. Retinol binding protein levels did not show any difference between anergic and reactive groups or the low absolute levels previously found in RA. ${ }^{23}$ Analysis in terms of anergy showed the anergic group to be lower in total calories (accounted for by low fat intake) and fibre than the reactive group but again not significantly so.

Table 1 Comparison of skin test results in controls and rheumatoid arthritis patients

\begin{tabular}{llll}
\hline & $\begin{array}{l}\text { Controls } \\
\text { Mean } \pm S D\end{array}$ & $\begin{array}{l}\text { RA } \\
\text { Mean } \pm S D\end{array}$ \\
\hline Number & 67 & 104 & $p$ \\
Age in years (range) & $57 \cdot 3 \pm 18 \cdot 2(41-86)$ & $59 \cdot 1 \pm 11 \cdot 17(44-81)$ & NS \\
Skin tests: mean sum score in mm (range) & $18 \cdot 0 \pm 9 \cdot 8(2-43)$ & $6 \cdot 3 \pm 7 \cdot 0(0-26.5)$ & $<0 \cdot 001$ \\
Number anergic (\%) & $0(0)$ & $35(36)$ & $<0 \cdot 001$ \\
\hline
\end{tabular}




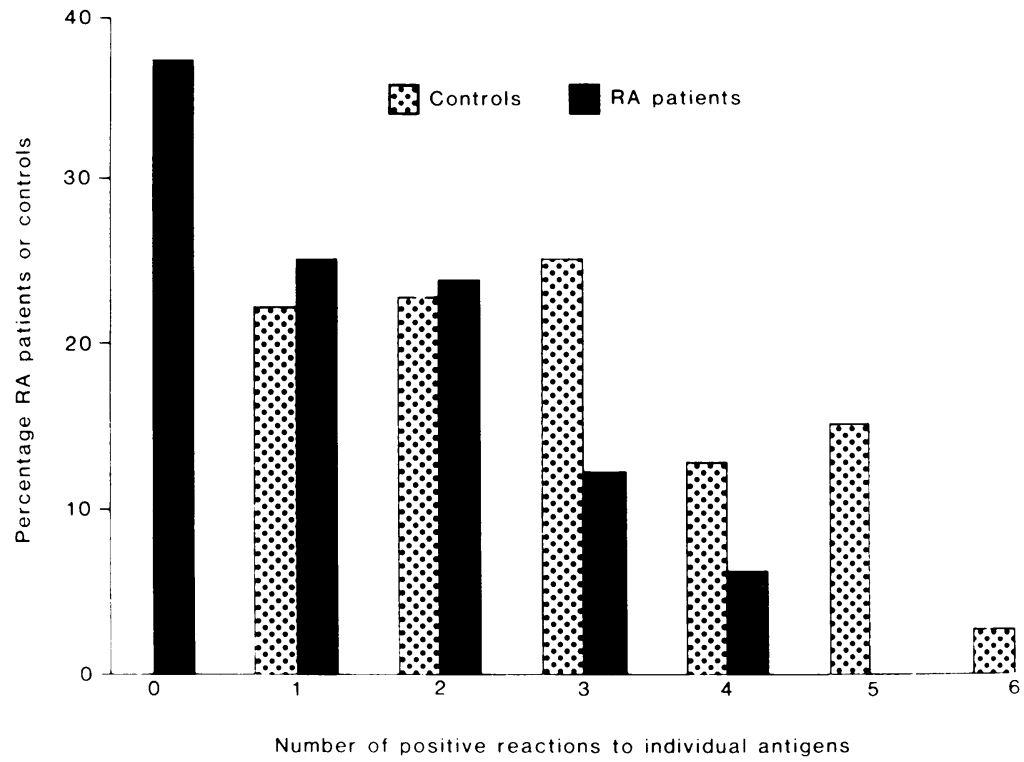

Fig. 1 Percentage of rheumatoid arthritis (RA) patients $(n=104)$ and controls $(n=67)$ with varying numbers of positive $(\geqslant 2 \mathrm{~mm}$ ) reactions to the 7 reagents.

Table 2 Comparison of clinical measures, disease activity, and drug therapy in anergic patients and patients with reactive rheumatoid arthritis

\begin{tabular}{lll}
\hline & $\begin{array}{l}\text { Anergic } \\
\text { Mean } \pm S D\end{array}$ & $\begin{array}{l}\text { Reactive } \\
\text { Mean } \pm S D\end{array}$ \\
\hline Number & 37 & 67 \\
Age (range) (years) & $60 \cdot 8 \pm 7 \cdot 2(53-73)$ & $58 \cdot 8 \pm 10 \cdot 5(44-81)$ \\
Male/Female & $9 / 28$ & $18 / 49$ \\
Clinical measures & $13 \cdot 2 \pm 10 \cdot 8(0 \cdot 5-29)$ & $11 \cdot 6 \pm 8 \cdot 9(0 \cdot 3-30)$ \\
$\quad$ Disease duration, years (range) & $30(81)$ & $49(73)$ \\
Number seropositive: DAT $>1 \cdot 16(\%)$ & $18(49)$ & $25(37)$ \\
Number with Nodules (\%) & $34(92)$ & $57(85)$ \\
Number with Erosions (\%) & $4 \cdot 84 \pm 3 \cdot 2(0-18)$ & $5 \cdot 10 \pm 4 \cdot 3(0-24)$ \\
Disease activity & $104 \cdot 6 \pm 89(0-360)$ & $93 \cdot 6 \pm 82(0-360)$ \\
Ritchie index (range) & $62 \cdot 9 \pm 37(11-105)$ & $49 \cdot 9 \pm 37(12-97)$ \\
Early morning stiffness (min) (range) & & $17(25)$ \\
ESR (mm) (range) & $8(21)$ & $15(22)$ \\
Drug therapy & $10(27)$ & $12(18)$ \\
$\quad$ Gold (\%) & $6(16)$ & \\
D-penicillamine (\%) & & \\
Prednisolone (<5mg/day) (\%) & & \\
\hline
\end{tabular}

There are no significant differences between the anergic and reactive groups for any of the results

$\mathrm{DAT}=$ differential agglutination titre

\section{Discussion}

Decreased DCH to recall antigens was demonstrated in 104 RA patients compared with 67 age and sex matched controls. This is a generalised rather than a selective (as postulated by Waxman et al. ${ }^{+}$) defect as evidenced by a significantly reduced sum score, a reduced mode score. and no RA patient having more than 4 positive reactions. There can the refore be little doubt that CMI, as measured by $\mathrm{DCH}$ to recall antigens, is seriously depressed in RA.

Waxman et al. ${ }^{4}$ found anergy was more common in patients with greater disease duration. whereas Andrianakos et al. ${ }^{3}$ found a correlation only between depressed $\mathrm{DCH}$ and increasing age. The current study found no measure capable of distinguishing the 

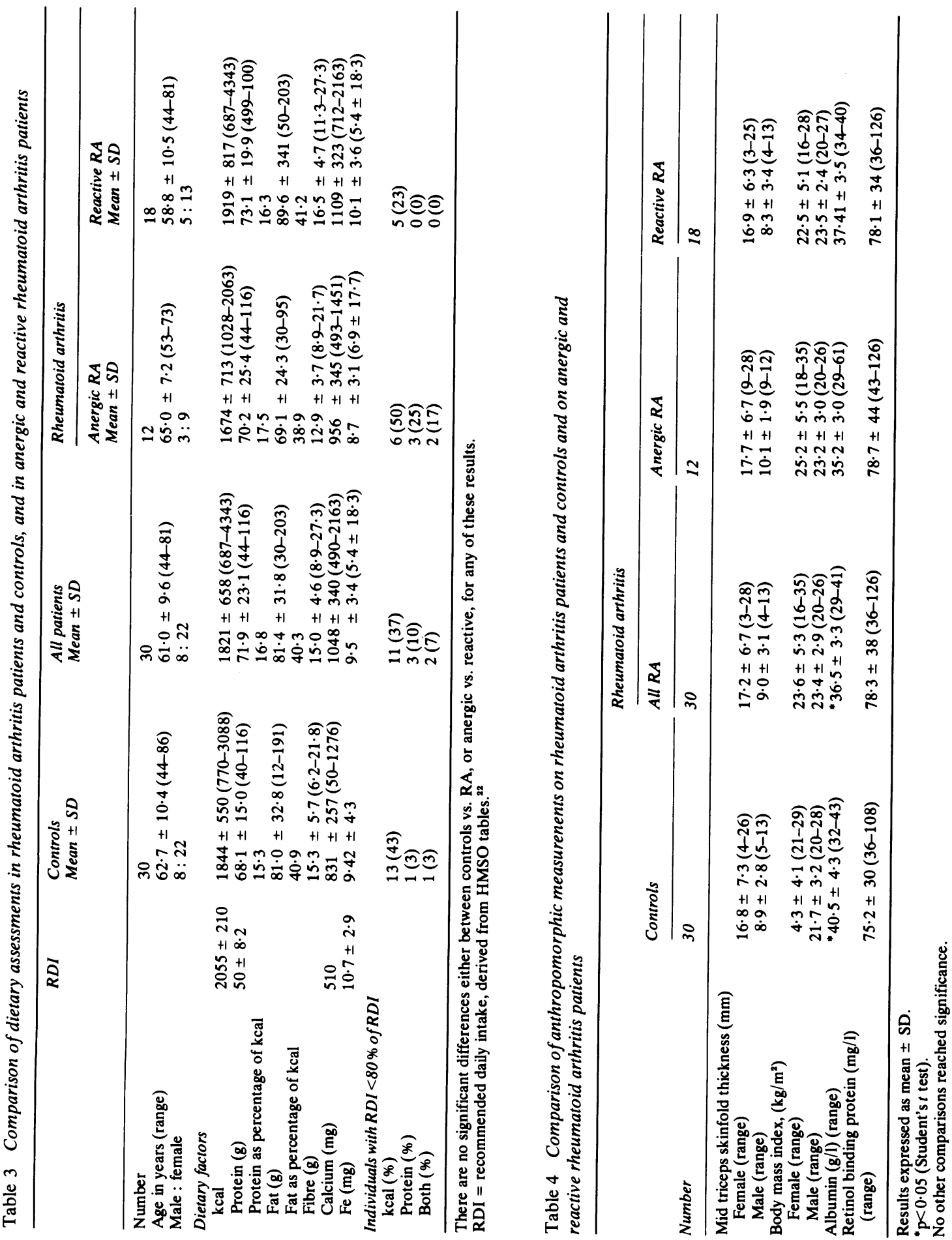
anergic and reactive groups. It has been shown that aspirin does not influence $\mathrm{DCH}$ in vivo, ${ }^{24}$ and no attempt was made to analyse results in terms of antiinflammatory drugs, at least one of which was being taken by every patient and some controls.

All patients in this study had well established RA, and the vexatious question of whether anergy precedes the establishment of disease in RA remains unanswered. A prospective study, now being undertaken by us, will hopefully provide information on this and help overcome the limitations inherent in cross-sectional studies, which may miss subtle changes of $\mathrm{DCH}$ with time and treatment. On the basis of this and other studies we must conclude that at present there is no consistent feature capable of predicting the depression of DCH in RA.

Unexpectedly the diet of RA patients (who were elderly and had lengthy disease duration) did not differ significantly from that of the control population, and the normal CMI and retinol binding protein confirm this lack of malnutrition.

The anergic group of patients had a non significant reduction in kcal, but they, like the reactive group, more than compensated for any diversion of protein to calorific purposes by their high protein intake.

In summary we have shown a significant generalised reduction in $\mathrm{DCH}$ to recall antigens in RA, with the lack of distinguishing features between anergic and reactive groups encouraging our belief that this may be an indicator of a fundamental abnormality of CMI in RA. The dietary and anthropomorphic measurements revealed no evidence for significant PEM in RA or for a difference between RA and controls in nutritional status. Diet did not play a major role in the anergy seen in RA. This is both reassuring, in that our patients are not suffering nutritionally as a result of their disease, and disappointing, in that there is little opportunity to improve CMI by dietary manipulation.

Part of this work was supported by a project grant from the Arthritis and Rheumatism Council.

\section{References}

1 Janossy G, Panayi G, Duke O, Bofill M, Poulter L, Goldstein G. Rheumatoid arthritis a disease of $T$ lymphocyte/macrophage immunoregulation. Lancet 1981; ii: 839-42.

2 Whaley K, Glenn A L A, MacSween R N M, et al. Immunological responses in Sjögren's syndrome and rheumatoid arthritis. Clin Exp Immunol 1971; 9: 721-32.
3 Andrianakos A A, Sharp J T, Person D A, Lidsky M D, Duffy J. Cell mediated immunity in rheumatoid arthritis. Ann Rheum Dis 1977; 36: 13-20.

4 Waxman J, Lockshin M D, Schnapp J J, Doneson I N. Cellular immunity in rheumatic diseases. Arthritis Rheum 1973; 16: 499-506.

5 Chandra R K. Immunology of nutritional disorders. London: Arnold, 1980: Chapter 3.

6 Chandra R K. Immunocompetence in undernutrition.J Pediatr 1972; 81: 1194-200.

7 Chandra R K. Lymphocyte subpopulations in malnutrition. Cytotoxic and suppressor cells. Pediatrics 1977; 59: 423-7.

8 Chandra R K. T and B lymphocyte sub populations and leucocyte terminal deoxynucleotidyl transferase in energy protein undernutrition. Acta Paediatr Scand 1979; 68: 841-5.

9 Geefhuysen J, Rosen E U, Katz J, Ipp T, Metz J. Impaired cellular immunity in kwashiorkor with improvement after therapy. $\mathrm{Br}$ Med J 1971; iv: 527-9.

10 Law D K, Dudrick S J, Abdou N I. Immunocompetence of patients with protein-calorie malnutrition. The effect of nutritional repletion. Ann Intern Med 1973; 79: 545-50.

11 Winick M. Nutrition in health and disease. New York: Wiley, 1980.

12 Goodhart R S, Shils M E, eds. Modern nutrition in health and disease. Philadelphia: Lea and Febiger, 1980.

13 Yelin E, Meenan R, Nevitt M, Epstein W. Work disability in rheumatoid arthritis. Effects of disease, social and work factors. Ann Intern Med 1980; 93: 551-6.

14 Lesourd B M, Roumiantzeff M, Moulias R, Biron G, Kniker W T. Reproducibility of delayed cutaneous hypersensitivity measured by Multitest. Allerg Immunol (Leipz) 1980; 8: 267-8.

15 Miller S D, Jones H E. Correlation of lymphocyte transformation with tuberculin skin-test sensitivity.Am Rev Resp Dis 1973; 107: 530-8.

16 Ritchie D M, Boyle J A, McInnes J M, et al. Clinical studies with an articular index for the assessment of joint tenderness. $Q J$ Med 1968; 147: 393-406.

17 Keys A, Fidanza F, Karvonen M J, Kimura N, Taylor H. Indices of relative weight and obesity. J Chron Dis 1972; 25: 329-43.

18 Frisancho A R. Triceps skinfold thickness and upper arm muscle size normal for assessment of nutritional status. Am J Clin Nutr 1974; 27: 1052-8.

19 Whitehead R G, Frood J D L, Poskitt E M J. Value of serum albumin measurements in nutritional surveys. Lancet 1971; ii: 287-9.

20 Shetty P S. Watrasiewicz K E, Jung R T, James W P T. Rapidturnover transport proteins: an index of subclinical proteinenergy malnutrition. Lancet 1979; ii: 230-2.

21 Paul A A, Southgate D A T, eds. McCance and Widdowson's The composition of food. 4th ed. London: HMSO, 1978.

22 Recommended daily amounts of food energy and nutrients for groups of people in UK. Report by the Committee on Medical Aspects of Food Policy. DHSS Report on Health and Social Services Number 15. London: HMSO, 1979.

23 Todesco S, Puynzi L, Meani A, Gambaci P F, Borsatti A. Retinol binding prote in in rheumatoid arthritis. Arthritis Rheum 1981; 24: $105-6$.

24 Duncan M W, Person D A, Rich R R, Sharp J T. Aspirin and delayed type hypersensitivity. Arthritis Rheum 1977; 20: 1174-8. 